Minimizing Three Hierarchically Criteria on a Single Machine

Adawiya A. Mahmood Al-Nuaimi

\title{
Minimizing Three Hierarchically Criteria on a Single Machine
}

\author{
Adawiya A. Mahmood Al-Nuaimi \\ Mathematics Department - College of Science - Diyala University \\ Received 13 December $2015 \quad$ Accepted 15 May 2016
}

\begin{abstract}
The problem of minimizing a function of three criteria maximum lateness, maximum earliness and sum of completion time in hierarchical method is discussed in this paper.A set of $n$ independent jobs has to be scheduled on a single machine that is continuously available from time zero onwards and that can handle no more than one job at a time. Job $j(j=1,2, \ldots, n)$ requires processing during a given positive uninterrupted time $\mathrm{p}_{\mathrm{j}}$. Some algorithms to find exact and best possible solutions are proposed for the problem of three criteria maximum lateness, maximum earliness and sum of completion time in hierarchical case.
\end{abstract}

Keywords: Hierarchical multicriteria, scheduling, single machine, Lexicographical multicriteria. 

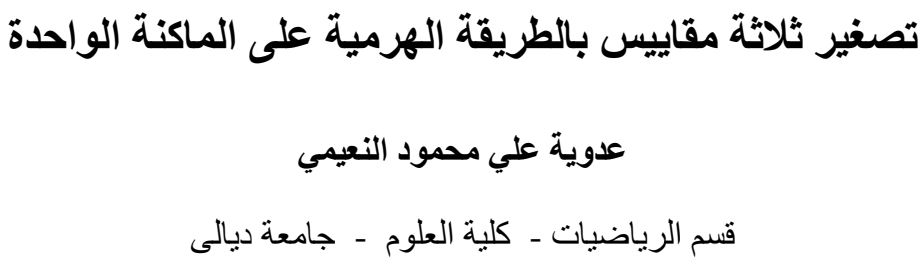

في هذا البحث نوقثت مسألة تصغير دالة مكونة من ثلاثة مقاييس وهي أعظم تأخير و أعظم تبكير ومجموع وقت الإتمام

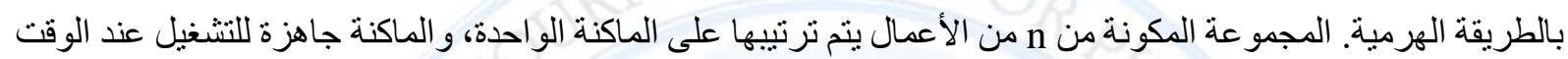

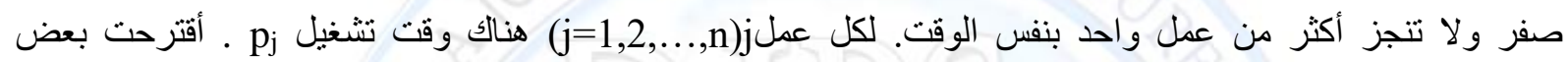
الخوارزميات لإيجاد الحلول المضبوطة وأفضل الحلول الممكنة للمسألة المكونة من ثلاثة مقاييس وهي أعظم تأخير وأعظم تبكير ومجموع وقت الإتمام في الحالة الهرمية. كلمات مفتاحية: مقاييس متعددة هرمية، جدولة، ماكنة واحدة، مقاييس متعددة حسب الأهية.

\section{$\underline{\text { Introduction }}$}

The basic scheduling problem can be described as finding for each of the tasks, which are also called jobs, an execution interval on one of the machines that are able to execute it, such that all side constraints are met; obviously, this should be done in such a way that the resulting solution, which is called a schedule, is best possible, that is, it minimizes the given objective function [3].Scheduling theory has been developed to solve problems occurring in for instance nurse scheduling [6].

In real life situations, decisions to be made are often constrained by specific requirements conflicting in nature. The decision making process gets increasingly more complicated with increment in the number of constraints. Modeling and development of solution methodologies for these scenarios have been the challenge for operations researchers from the outset. A variety of algorithms and formulations has been developed for various classes of problems [9].

In this study, the one machine case is considered because the one machine problem provides a useful laboratory for the development of ideas for heuristics and interactive procedure that may prove to be useful in more general models. 


\section{Minimizing Three Hierarchically Criteria on a Single Machine}

\section{Adawiya A. Mahmood Al-Nuaimi}

There are two approaches for the multicriteria problems; the hierarchical and the simultaneous approach. In the hierarchical approach, one of the two criteria is considered as the primary criterion and the other one as the secondary criterion. The problem is to minimize the primary criterion while breaking ties in favor of the schedule that has the minimum secondary criterion value. In the simultaneous approach, two criteria are considered simultaneously. This approach typically generates all efficient schedules and selects the one that yields the best composite objective function value of the two criteria. Most multicriteria scheduling problems are NPhard in nature [1].

Nelson et al. [8] presented some algorithms for the three, two criteria problems utilizing mean flow time $\mathrm{F}$, maximum tardiness $\mathrm{T}_{\max }$ and number of tardy job $\mathrm{n}_{\mathrm{T}}$. Hoogeveen [4] presented an algorithm to minimize a non-decreasing function of $\mathrm{K}$ performance regular criteria. Erne [2] gave a heuristic method for multicriteria scheduling problem with sequencing dependent setup time for minimizing the weighted sum of total completion time, maximum tardiness and maximum earliness by integer programming model.

A schedule $\sigma$ defines for each job j its completion time $\mathrm{C}_{\mathrm{j}}(\sigma)$ such that the jobs do not overlap in their execution. The cost of completing $j$ at time $C_{j}(j=1,2, \ldots, n)$ is measured by penalty functionf ${ }_{j}$.

In this paper the multicriteria problem concerns the hierarchical minimization of the performance measure sum of completion time $\sum \mathrm{C}_{j}$ and maximum $\cos t \mathrm{f}_{\max }$, maximum cost defines $f_{j}\left(C_{j}\right)$, where each $f_{j}$ denotes regular or irregular cost function; regular means that $f_{j}\left(C_{j}\right)$ does not decrease when $\mathrm{C}_{\mathrm{j}}$ increases such as $\mathrm{T}_{\max }, \mathrm{L}_{\max }$ and $\sum \mathrm{C}_{\mathrm{j}}$. Otherwise the function is called irregular such as $\mathrm{E}_{\max }$. 


\section{Minimizing Three Hierarchically Criteria on a Single Machine}

\section{Adawiya A. Mahmood Al-Nuaimi}

\section{Notation and basic concepts}

In this paper the notation is used for single machine, $j$ obs $j(j=1,2, \ldots, n)$ have:

$\mathrm{N}$ : set of jobs.

$\mathrm{n}$ : the number of jobs in a known sequence.

$\mathrm{p}_{\mathrm{j}}$ : a processing time for job $\mathrm{j}$.

$d_{j}$ : the date when the job $\mathrm{j}$ should ideally be completed.

$\bar{d}_{\mathrm{j}}:$ the deadline for job $\mathrm{j}$.

$\mathrm{C}_{\mathrm{j}}$ : the completion time of job $\mathrm{j}$.

$\mathrm{C}_{1}=\mathrm{p}_{1}$

$C_{j}=C_{(j-1)}+p_{j}, j=2, \ldots, n$.

$\mathrm{s}_{\mathrm{j}}=\mathrm{d}_{\mathrm{j}}-\mathrm{p}_{\mathrm{j}}:$ the slack time of job $\mathrm{j}$.

$L_{j}=C_{j}-d_{j}:$ the lateness of job $j$.

$E_{j}=\max \left\{0, d_{j}-C_{j}\right\}$ : the earliness of job $j$.

$\mathrm{C}_{\max }=\max _{j}\left\{\mathrm{C}_{\mathrm{j}}\right\}:$ maximum completion time.

$E_{\max }=\max _{j}\left\{E_{j}\right\}:$ maximum earliness.

$\mathrm{L}_{\max }=\max _{j}\left\{\mathrm{~L}_{\mathrm{j}}\right\}:$ maximum lateness.

$\mathrm{SPT}=$ shortest processing time rule, that is, sequencing the jobs in non-decreasing order of their processing times.

$\mathrm{EDD}=$ earliest due date rule, that is, sequencing the jobs in non-decreasing order of their due dates.

\section{Theorem (1) [7]}

The $1 / / \mathrm{f}_{\max }$ problem is minimized as follows:

While there are unassigned jobs, assign the job that has minimum cost when scheduled in the last unassigned position in the schedule.

\section{Theorem (2) [5]}

The $1 / / \mathrm{E}_{\max }$ problem is solved by sequencing the jobs according to the minimum slack time (MST) rule, that is, in non-decreasing order of $d_{j}-p_{j}$.

\section{Definition [4]}




\section{Minimizing Three Hierarchically Criteria on a Single Machine}

\section{Adawiya A. Mahmood Al-Nuaimi}

Hierarchical minimization : the performance criteria $\mathrm{f}_{1}, \mathrm{f}_{2}, \ldots, \mathrm{f}_{\mathrm{k}}$ are indexed in order of decreasing importance. First, $\mathrm{f}_{1}$ is minimized. Next, $\mathrm{f}_{2}$ is minimized subject to the constraint that the schedule has minimal $f_{1}$ value. If necessary, $f_{3}$ is minimized subject to the constraint that the values for $f_{1}$ and $f_{2}$ are equal to the values determined in the previous step.

The $1 / / \operatorname{Lex}\left(\sum_{j=1}^{n} C_{j}, L_{\max }, E_{\max }\right)$ problem

This problem can be defined as follows:

$$
\operatorname{Min}\left\{\mathrm{E}_{\max }\right\}
$$

S.t.

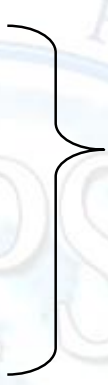

$\sum_{\mathrm{j}=1}^{\mathrm{n}} \mathrm{C}_{\mathrm{j}}=\mathrm{C}^{*}, \mathrm{C}^{*}=\sum_{\mathrm{j}=1}^{\mathrm{n}} \mathrm{C}_{\mathrm{j}}(\mathrm{SPT})$

$\mathrm{L}_{\max } \leq \mathrm{L}, \quad \mathrm{L} \in\left[\mathrm{L}_{\max }(\mathrm{EDD}), \mathrm{L}_{\max }(\mathrm{SPT})\right]$

Since in this problem $(\mathrm{P} 1)$, the $\sum_{\mathrm{j}=1}^{\mathrm{n}} \mathrm{C}_{\mathrm{j}}$ is the more important function and should be optimal, then the following algorithm (CLE) gives the optimal required result.

\section{Algorithm (CLE)}

Step (1): Order the jobs by SPT rule and calculate $\left(\sum_{\mathrm{j}=1}^{\mathrm{n}} \mathrm{C}_{\mathrm{j}}, \mathrm{L}_{\max }, \mathrm{E}_{\max }\right)$.

Step (2): If there exist a tie (jobs with equal processing times), order these jobs by EDD rule and if a tie is still (jobs with equal due dates), order these jobs by MST rule.

Example (1):Consider the problem (P1) with the following data.

\begin{tabular}{|l|l|l|l|l|l|}
\hline $\mathrm{j}$ & 1 & 2 & 3 & 4 & 5 \\
\hline $\mathrm{p}_{\mathrm{j}}$ & 2 & 2 & 6 & 1 & 8 \\
\hline $\mathrm{d}_{\mathrm{j}}$ & 17 & 7 & 6 & 5 & 8 \\
\hline $\mathrm{s}_{\mathrm{j}}$ & 16 & 6 & 0 & 3 & 0 \\
\hline
\end{tabular}




\section{Adawiya A. Mahmood Al-Nuaimi}

The SPT rule gives the schedules $(4,1,2,3,5)$ and $(4,2,1,3,5)$, the schedule $(4,2,1,3,5)$ is chosen according to algorithm (CLE) that gives minimum $\sum_{j=1}^{n} C_{j}$ with $\left(\sum_{j=1}^{n} C_{j}, L_{\max }, E_{\max }\right)=(39$, $11,12)$.

\section{The $1 / / \operatorname{Lex}\left(\sum_{j=1}^{n} C_{j}, E_{\max }, L_{\max }\right)$ problem}

This problem can be defined as follows:

$\operatorname{Min}\left\{\mathrm{L}_{\max }\right\}$

S.t.

$\sum_{j=1}^{n} C_{j}=C^{*}, C^{*}=\sum_{j=1}^{n} C_{j}(S P T)$

$\mathrm{E}_{\max } \leq \mathrm{E}, \mathrm{E} \in\left[\mathrm{E}_{\max }(\mathrm{MST}), \mathrm{E}_{\max }(\mathrm{SPT})\right]$

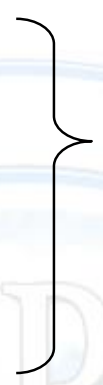

Since in this problem $(\mathrm{P} 2)$, the $\sum_{\mathrm{j}=1}^{\mathrm{n}} \mathrm{C}_{\mathrm{j}}$ is the more important function and should be optimal, then the following algorithm (CEL) gives the optimal required result.

\section{Algorithm (CEL)}

Step(1): Order the jobs by SPT rule and calculate $\left(\sum_{j=1}^{n} C_{j}, E_{\max }, L_{\max }\right)$.

Step(2): If there exist a tie (jobs with equal processing times), order these jobs by MST rule and if a tie is still (jobs with equal slack times), order these jobs by EDD rule.

Example (2): Consider the problem (P2) with the following data.

\begin{tabular}{|l|l|l|l|l|l|}
\hline $\mathrm{j}$ & 1 & 2 & 3 & 4 & 5 \\
\hline $\mathrm{p}_{\mathrm{j}}$ & 2 & 2 & 4 & 9 & 4 \\
\hline $\mathrm{d}_{\mathrm{j}}$ & 9 & 9 & 10 & 18 & 4 \\
\hline $\mathrm{s}_{j}$ & 7 & 7 & 6 & 9 & 0 \\
\hline
\end{tabular}

The SPT rule gives the schedules $(1,2,3,5,4),(2,1,3,5,4),(1,2,5,3,4)$ and $(2,1,5,3,4)$, the schedule $(1,2,5,3,4)$ is chosen according to algorithm $(C E L)$ that gives $\left(\sum_{\mathrm{j}=1}^{\mathrm{n}} \mathrm{C}_{\mathrm{j}}, \mathrm{E}_{\max }, \mathrm{L}_{\max }\right)$ $=(47,7,4)$. 


\section{Minimizing Three Hierarchically Criteria on a Single Machine}

\section{Adawiya A. Mahmood Al-Nuaimi}

The $1 / / \operatorname{Lex}\left(L_{\max }, \sum_{j=1}^{n} C_{j}, E_{\max }\right)$ problem

This problem can be defined as follows:

$\operatorname{Min}\left\{E_{\max }\right\}$

S.t.

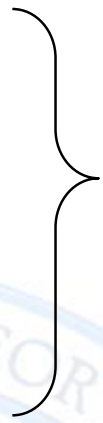

$\mathrm{L}_{\max }=\mathrm{L}^{*}, \mathrm{~L}^{*}=\mathrm{L}_{\max }(\mathrm{EDD})$

$\sum_{\mathrm{j}=1}^{\mathrm{n}} \mathrm{C}_{\mathrm{j}} \leq \mathrm{C}^{*}, \mathrm{C}^{*} \in\left[\sum_{\mathrm{j}=1}^{\mathrm{n}} \mathrm{C}_{\mathrm{j}}(\mathrm{SPT}), \sum_{\mathrm{j}=1}^{\mathrm{n}} \mathrm{C}_{\mathrm{j}}(\mathrm{EDD})\right]$

Since in this problem (P3), the $\mathrm{L}_{\max }$ is the more important function and should be optimal, then the following algorithm (LCE) gives the best possible solution.

\section{Algorithm (LCE)}

Step (1): Solve $1 / / \mathrm{L}_{\max }$ problem to find $\mathrm{L}^{*}$.

Step(2): Determine $\bar{d}_{\mathrm{j}}=\mathrm{d}_{\mathrm{j}}+\mathrm{L}^{*}$ and $\mathrm{s}_{\mathrm{j}}=\mathrm{d}_{\mathrm{j}}-\mathrm{p}_{\mathrm{j}} \forall \mathrm{j} \in \mathrm{N}, \mathrm{N}=\{1,2, \ldots, \mathrm{n}\}$.

$\operatorname{Step}(3)$ : Let $\mathrm{t}=\sum_{\mathrm{j}=1}^{\mathrm{n}} \mathrm{p}_{\mathrm{j}}, \mathrm{k}=\mathrm{n}$.

Step(4): Find a job $\mathrm{j} \in \mathrm{N}$ satisfies $\bar{d}_{\mathrm{j}} \geq \mathrm{t}$ ( if there exist a tie choose the job with biggest processing time and if a tie is still, choose the job with biggest slack time ).

Step(5): Set $\mathrm{t}=\mathrm{t}-\mathrm{p}_{\mathrm{j}}, \mathrm{k}=\mathrm{k}-1, \mathrm{~N}=\mathrm{N}-\left\{\mathrm{j}^{*}\right\}, \sigma=(\sigma(\mathrm{k}), \sigma)$, if $\mathrm{N}=\varphi$ go to step(6) else go to $\operatorname{step}(4)$.

Step(6): For a schedule $\sigma$ compute $\mathrm{L}_{\max }, \sum_{\mathrm{j}=1}^{\mathrm{n}} \mathrm{C}_{\mathrm{j}}$ and $\mathrm{E}_{\max }$.

Example(3):Consider the problem (P3) with the following data.

\begin{tabular}{|l|l|l|l|l|l|}
\hline $\mathrm{j}$ & 1 & 2 & 3 & 4 & 5 \\
\hline $\mathrm{p}_{\mathrm{j}}$ & 2 & 1 & 5 & 9 & 9 \\
\hline $\mathrm{d}_{\mathrm{j}}$ & 3 & 11 & 12 & 10 & 9 \\
\hline $\mathrm{s}_{\mathrm{j}}$ & 1 & 10 & 7 & 1 & 0 \\
\hline
\end{tabular}

$\mathrm{L}^{*}=14, \mathrm{t}=26$ 


\section{Minimizing Three Hierarchically Criteria on a Single Machine}

\section{Adawiya A. Mahmood Al-Nuaimi}

$\bar{d}_{1}=17, \bar{d}_{2}=25, \bar{d}_{3}=26, \bar{d}_{4}=24, \bar{d}_{5}=23$

\begin{tabular}{|l|l|l|}
\hline $\mathrm{j}$ & $\mathrm{t}$ & $\mathrm{j}^{*}$ \\
\hline 1 & 26 & 3 \\
\hline 2 & 21 & 4 \\
\hline 3 & 12 & 5 \\
\hline 4 & 3 & 1 \\
\hline 5 & 1 & 2 \\
\hline
\end{tabular}

Hence the schedule $(2,1,5,4,3)$ gives $\left(\mathrm{L}_{\max }, \sum_{\mathrm{j}=1}^{\mathrm{n}} \mathrm{C}_{\mathrm{j}}, \mathrm{E}_{\max }\right)=(14,63,10)$ according to algorithm (LCE).

\section{Conclusions}

For the multicriteria scheduling problem $1 / /\left(f_{\max }, g_{\max }, \sum h_{j}\right)$, some algorithms and procedure to find exact and best possible solution for the hierarchical case is proposed.

It is hoped that the contribution of this paper would provide an incentive research effort in this multicriteria field especially three hierarchically criteria.

A future research topic would involve experimentation with the following machine scheduling problems: $1 / / \operatorname{Lex}\left(\mathrm{E}_{\max }, \sum_{\mathrm{j}=1}^{\mathrm{n}} \mathrm{C}_{\mathrm{j}}, \mathrm{L}_{\max }\right)$ and $1 / / \operatorname{Lex}\left(\mathrm{E}_{\max }, \mathrm{L}_{\max }, \sum_{\mathrm{j}=1}^{\mathrm{n}} \mathrm{C}_{\mathrm{j}}\right)$.

\section{References}

1. Akande S., Oluleye A. E. and Oyetunji E. O., "Reducibility of some multicriteria scheduling problems to bicriteria scheduling problems", International Conference on Industrial Engineering and Operations Management 7(9), 642-651 (2014).

2. Eren T.,"A multi-criteria scheduling with sequence-dependent setup times", Applied Mathematical Sciences, 1,58, 2883-2894 (2007).

3. Hoogeveen H., "Invited review of multicriteria scheduling", European Journal of Operational Research 167, 592-623 (2005). 


\section{Minimizing Three Hierarchically Criteria on a Single Machine}

\section{Adawiya A. Mahmood Al-Nuaimi}

4. Hoogeveen H., " Single machine scheduling to minimize a function of two or three maximum cost criteria", Journal of Algorithms, 21, 415-433 (1996).

5. Hoogeveen H., "Minimizing maximum earliness and maximum lateness on a single machine", CWI, BS-R9001 (1990).

6. Kumar B.S., Nagalakshmi G. and Kumaraguru S., "A shift sequence for nurse scheduling using linear programming problem", Journal of Nursing and Health Science 3, 24-28 (2014).

7. Lawler E. L., "Optimal sequencing of a single machine subject to precedence constraints", Management Science 19/5, 544-546 (1973).

8. Nelson R. T., Sarin R. K. and Daniels R. L., "Scheduling with multiple performance measures: The one-machine case", Management Science 32, 464-479 (1986).

9. Prakash D., "Bi-criteria scheduling problems on parallel machines", M.Sc. Thesis, Virginia Polytechnic Institute and State University (2007). 